\title{
PERCEPÇÃO DAS FAMÍLIAS MULTIPROBLEMÁTICAS POBRES SOBRE AS SUAS COMPETÊNCIAS ${ }^{1}$
}

\author{
Liliana Sousa ${ }^{2}$ \\ Cláudia Ribeiro ${ }^{3}$
}

\section{Agradecimentos}

As autoras agradecem a Sílvia Pereira, Susana Pires e Daniela Figueiredo a colaboração na recolha dos dados.

Resumo: As famílias multiproblemáticas pobres são descritas como disfuncionais e desorganizadas, sendo rara a referência a competências. Porém, a activação de competências tem demonstrado ser um importante instrumento de intervenção. Assim, neste estudo exploratório procura-se identificar a percepção dessas famílias sobre o que funciona no seu agregado. Para tal administrou-se uma entrevista semiestruturada a 60 chefes de famílias pobres (32 multiproblemáticas e 28 não multiproblemáticas). Os resultados salientam: a união familiar, o vínculo filial e a entreajuda como aspectos positivos; os objectivos de vida centram-se na melhoria das condições de habitação e do estado de saúde; os acontecimentos que permitiram à família melhorar de vida centram-se em arranjar um emprego estável e na melhoria do estado de saúde. As famílias multiproblemáticas pobres emergem como competentes, embora algo bloqueadas no uso dessas competências.

Palavras chave: famílias multiproblemáticas, pobreza, competências, intervenção.

Multi-problematic poor families' perception of their own competences (abstract): Multi-problem poor families have been characterized in the literature and research as dysfunctional and disorganized. The mention competencies are rare. However the activation of competencies has prove to be an important tool for intervention, thus in this exploratory study we attempt to identify the families perception of what works in their relationship. A semi-structured interview was administered to

\footnotetext{
${ }^{1}$ Estudo parte de um projecto financiado pela FCT (Fundação para a Ciência e Tecnologia). Projecto n. ${ }^{\circ} 39644 / \mathrm{SOC} / 2001$.

2 Psicóloga, Professora Auxiliar com Agregação da Secção Aut. de Ciências da Saúde, Universidade de Aveiro, 3810-193 Aveiro, Portugal, E.mail: lilianax@cs.ua.pt

${ }^{3}$ Psicóloga, bolseira de investigação na Secção Autónoma de Ciências da Saúde da Universidade de Aveiro.
} 
60 heads of poor households: 32 of multi-problem families and 28 of non multi-problem. The findings suggest that: the positive aspects are family cohesion, filial attachment and mutual support; families goals are centred on the improvement of their housing conditions and their health status; the events which allowed the family to live better were getting a more stable job and the improvement of the health status. Multi-problem poor families emerge as competent, but some how paralysed in the use of their competencies.

\section{Introdução}

A literatura e investigação sobre famílias multiproblemáticas pobres têm enfatizado os défices, a descrição dos problemas e os modos de disfuncionamento familiar. Tal decorre, por um lado, da perspectiva deficitária dominar a intervenção e, por outro, da dificuldade em valorizar competências em famílias que vivem conjunturas de elevada vulnerabilidade. Contudo, após a demonstração de que as famílias não são susceptíveis de uma regulação impositiva pelo exterior (que não considere o seu potencial de auto-regulação) (Maturana \& Varela, 1980), o enfoque nas competências tem vindo a constituir-se como um sólido instrumento de intervenção. Nesta linha, a intervenção enfatiza as competências dos clientes no sentido de resolverem as suas queixas e atingirem os seus objectivos, cabendo ao interventor a tarefa de aceder a essas capacidades e facilitar o seu uso (O'Hanlon \& Weiner-Davis, 1989).

É neste cenário que se encerra a principal finalidade deste estudo exploratório: conhecer a percepção das famílias multiproblemáticas pobres sobre as suas competências. A relevância deste objectivo é sublinhada por a centração nas competências envolver o reconhecimento pelas famílias das próprias capacidades (e não apenas a atribuição pelos profissionais) (Ausloos, 1996). Os resultados serão pertinentes na identificação de competências, que possam ser activadas no sentido de ajudar as famílias a utilizarem as próprias capacidades e, assim, melhorarem o seu bem-estar. Com o propósito de estudar este tópico, construiu-se uma entrevista semiestruturada, que foi administrada ao "chefe de família" (elemento de ligação com os serviços de protecção social). Optámos por recolher estes dados junto de famílias multiproblemáticas pobres e de famílias pobres não multiproblemáticas, no sentido de destrinçar pobreza de desorganização familiar. 


\section{A importância das competências}

As abordagens positivistas concebiam a patologia como individual, sem influência do meio cultural ou social. A solução estava nas mãos do especialista (interventor), exterior ao sistema (neutro), que domina técnicas e estratégias de intervenção. O objectivo é a cura, que se atinge a partir de um diagnóstico exaustivo que caracteriza a patologia e identifica as causas. A solução (única) está em eliminar as causas.

Com o advento da 1. ${ }^{a}$ cibernética, o sintoma converte-se num comportamento (mensagem) coerente e com uma função na família (mecanismo homeostático). O conceito de patologia torna-se inexacto, sendo substituído por disfuncionalidade, pois o que está em causa é um jogo relacional homeostático com o propósito da manutenção. A intervenção (tal como a avaliação) centra-se nas relações familiares (e não no sujeito), mantendo o interventor no papel de especialista, exterior ao sistema e objectivo, detendo o poder na relação terapêutica. As famílias são percebidas como tendendo para a estabilidade, o que as torna resistentes à mudança, que tem de ser induzida de fora.

Com os modelos positivistas e os derivados da $1 .^{\text {a }}$ cibernética, a intervenção orientou-se para o passado, buscando as raízes dos sintomas actuais na infância do cliente ou nas relações familiares, enfatizando o papel das competências dos profissionais para resolver os problemas dos clientes. A família é esvaziada de competências e do conhecimento de si, ficando numa posição de recipiente passivo da acção do interventor (cf. Haley, 1996). Esta perspectiva deu contributos valiosos, mas desenvolvimentos posteriores demonstram as suas limitações.

A emergência da 2. ${ }^{a}$ cibernética, principalmente, através da noção de autonomia (Maturana \& Varela, 1980), demonstra que os sistemas não são comandados do exterior, pois a troca comunicacional (abertura informacional) é acompanhada por autonomia organizativa (fecho operacional). Daqui decorre que os sistemas seguem as suas regras e fazem as próprias escolhas, logo não são reguláveis do exterior por intermédio da acção de um interventor, mas a família tem competências para a mudança. Os mesmos autores demonstraram que o mundo dos factos é re-criado, então o observador participa activamente no que observa, logo o interventor não é neutro, mas utiliza os seus padrões éticos, estéticos e pragmáticos na análise das situações (sistemas observantes) (Fruggeri, 1996). Em consequência, o papel do interventor e do cliente sofrem transformações: desenha-se uma postura heterárquica (Andersen, 1995), em que o interventor tem como competência ser um catalisador de mudança (identifica e amplia) e o cliente é especializado na sua vivência e tem competências para evoluir. Nesta linha, enfatizam-se as competências da família, atribuindo-se relevo 
a uma acção co-construtiva, onde família e terapeuta, num só sistema, co-criam novas soluções.

Em consequência, nas últimas décadas, vários autores deram voz à importância das forças das famílias e à ideia de que todas as famílias têm competências. Nagy e Zuk (1967) destacam a conotação positiva e a exploração do sistema de valores da família. Whitaker (1989) considera que, ao introduzir caos numa família pela via terapêutica, os membros da família podem descobrir a sua força latente. Ausloos (1996) advoga que todas as famílias têm competências e que a cada família só se podem colocar problemas para os quais tenha recursos e capacidades de os solucionar. O'Hanlon (1993) escreve sobre a terapia das possibilidades, destacando que se deve procurar o que é possível na família e não o que é impossível, mas seria importante que acontecesse. Shazer (1999) coloca os clientes a descobrir soluções que funcionaram no passado ou no presente, para que o interventor possa colaborar na construção de soluções futuras.

Nesta linha, as denominadas famílias disfuncionais estão, apenas, parcialmente paralisadas ou bloqueadas em padrões repetitivos de organização que não funcionam, mas que dão algum sentido de segurança porque são habituais. Para as ajudar a ganhar o controlo sobre as suas vidas, os profissionais têm de focar as suas competências (Shazer, Berg, Lipchik, Nunnaly, Molnar, Gingerich \& Weiner-Davis, 1986; O'Hanlon \& Weiner-Davis, 1989; Ausloos, 1996).

\section{As competências das famílias}

A literatura e a investigação têm-se debruçado sobre vários tópicos relacionados com as competências numa família, utilizando várias designações: famílias saudáveis (healthy), capazes (capable), fortes (strenghts) e competentes (cf. Barnhill, 1979; Saleebey, 1996). Estas nomenclaturas apontam para uma dicotomia: famílias saudáveis versus doentes, ou fortes versus frágeis. Porém, tomando o enquadramento teórico exposto, torna-se mais adequado utilizar a designação: competências das famílias. Deste modo, afirma-se que competências e incompetências existem em todas as famílias (cf. Saleebey, 2001; Shazer et al., 1986). Esta terminologia afasta o mito da família normal, feliz e harmoniosa, uma vez que todas as famílias lutam com problemas, sejam eles normativos (inerentes ao desenvolvimento) ou inesperados (como o desemprego) (Hoffman, 1971).

Contudo, os estudos sobre as famílias capazes, fortes e saudáveis produziram um conjunto de dimensões úteis quando se procuram as competências de uma família, pois demonstram o que tende a ser eficaz na vida familiar. Entre o conjunto de elementos mais comuns destacam-se (cf. 
Beavers, 1985; Epstein, Bishop, Miller \& Keitner, 1993; Olson, 1990; Satir, 1967; Stinnett, 1979; Curran, 1983; Kelley, 1994; Olson, Larsen \& McCubbin, 1989): a comunicação, o encorajamento (apreciação e compromisso), a orientação religiosa, a adaptabilidade, o relacionamento social, os papéis claros e o tempo partilhado.

A comunicação nas famílias competentes distingue-se pela clareza, abertura e frequência (cf. Epstein et al., 1993; Olson, 1990). O encorajamento (apoio e reconhecimento), apreciação (reforço positivo entre os membros) e compromisso (sentido de unidade e identidade) são atributos muito próximos da coesão (sentimento de proximidade e vinculação dos membros da família) (Olson, Larsen \& McCubbin, 1989). A orientação religiosa, ou bem-estar espiritual, focaliza o sistema de valores partilhado pelos membros, podendo tomar várias formas: cumprimento de alguma forma religiosa, envolvimento em causas válidas ou aderência a um código moral (Stinnett, 1979). A adaptabilidade é a capacidade dum sistema familiar mudar a sua estrutura de poder e regras em resposta a stress situacional e desenvolvimental (Olson, Larsen \& McCubbin, 1989). O relacionamento social refere-se ao envolvimento da família com sistemas externos (por exemplo, amigos e vizinhos), sendo uma forma de garantir maior diversidade de recursos. Os papéis claros são essenciais para a adaptação à mudança, pois, com uma estrutura clara, mas flexível, os membros da família estão conscientes das responsabilidades na e para a família (Epstein et al., 1993). O tempo partilhado refere-se à quantidade e qualidade dos momentos que a família passa em conjunto e o quanto aprecia esse tempo.

Enquanto nesta perspectiva (mais clássica) são definidas dimensões das famílias competentes, do ponto de vista das abordagens centradas nas competências (derivadas da $2 .^{\mathrm{a}}$ cibernética) a ênfase coloca-se mais na acção. Ou seja, a identificação das competências das famílias funda-se em ajudá-las a reconhecer as próprias capacidades (Shazer \& Berg, 1997), como forma de responder a um problema que faz a família sentir-se bloqueada. De facto, a demasiada concentração nos problemas, impede os sistemas de perscrutar soluções e perceber que competências têm para dissolver os problemas (Dallos \& Hamilton-Brown, 2000). Nesta linha, é importante reconhecer as competências perante um problema: encorajar conversações sobre os objectivos a atingir e as soluções possíveis, pois, enquanto as pessoas se concentram nos problemas, sentem-se incompetentes e incapazes (Shazer \& Berg, 1997). 


\section{As competências das famílias multiproblemáticas pobres}

Comecemos por destrinçar os conceitos de multiproblematicidade e pobreza, principalmente, porque na prática são, não raramente, utilizados como sinónimos, resultando na implementação de intervenções inadequadas. As famílias multiproblemáticas têm sido, frequentemente, associadas à pobreza e a baixos níveis socioeconómicos, contudo, as famílias multiproblemáticas pobres constituem apenas o grupo mais visível deste conjunto de agregados (Cunningham \& Henggeler, 1999), que pode ser encontrado em todos os contextos sociais, culturais e económicos. Paralelamente, ser pobre não significa necessariamente ser disfuncional, porém a pobreza é um factor que pode forçar mesmo famílias saudáveis a bloquearem, especialmente quando há contextos que as mantêm numa posição de pobreza e pouco poder (Hines, 1989). Assim, pobreza e multiproblematicidade podem ocorrer na mesma família, mas não necessariamente.

O conceito de família multiproblemática tem sido operacionalizado da seguinte forma (Cancrini, Gregorio \& Nocerino, 1997: 52/53): presença simultânea em dois ou mais membros da família de comportamentos problemáticos severos e estáveis no tempo; insuficiência grave, sobretudo dos pais, nas actividades funcionais e relacionais e no desenvolvimento familiar; reforço entre os aspectos anteriores; fragilidade dos limites, própria de um sistema em que a presença de técnicos e outras figuras externas é forte; estruturação de uma relação crónica de dependência com os serviços sociais; desenvolvimento de algumas modalidades pouco usuais de comportamentos sintomáticos nos sujeitos (por exemplo, toxicodependências tipo D - sociopáticas). De facto, as descrições e os estudos sobre as famílias multiproblemáticas têm incidido, quase somente, nos défices e patologias, raramente tocando as competências. Provavelmente, esta temdência decorre dos contornos dramáticos da vida destas famílias, que dificulta aos elementos externos (com destaque para os profissionais) valorizar os aspectos positivos, ofuscados pelos problemas (Sousa, 2005). Todavia, é possível delinear duas abordagens relativas às competências nestas famílias: a hipótese compensatória (Linares, 1997) e o reenquadramento positivo (Madsen, 1999).

Linares (1997), num estudo realizado num bairro de Barcelona em que se interveio dum ponto de vista sistémico com famílias multiproblemáticas, descreve a hipótese compensatória. $\mathrm{O}$ autor sugere que alguns Mecanismos correctores partem, paradoxalmente, da desarmonia conjugal, introduzindo um factor de relativização na deterioração parental: por vezes, o desacordo entre os pais abre fissuras por onde pode fluir a protecção e nutrição emocional dos filhos. E não é raro que tal ocorra nos momentos de maior dificuldade para a família e de mais intenso perigo para os filhos. De 
facto, é comum o reconhecimento de que os pais amam os filhos, embora sejam incompetentes em algumas tarefas, mas tal ocorre porque não sabem fazer melhor, já que os seus modelos de referência foram, igualmente, instáveis e inseguros. Esta hipótese compensatória verifica-se, igualmente, quando a desarmonia parental e conjugal têm a qualidade de facilitar e promover a intervenção externa (informal e formal).

Madsen (1999) alerta para o facto de que as histórias de vida das famílias multiproblemáticas pobres são quase sempre lidas através da lente do défice, mas, quando enquadradas numa perspectiva mais positiva, permitem descortinar competências. $\mathrm{O}$ autor sublinha que estas são famílias multi-stressadas, pois vivem momentos de stress normativo e não normativo frequentes e, até, simultâneos. A necessidade de responderem a sucessivas crises, procurando novas soluções para recentes circunstâncias, dá-lhes a aparência de caóticas e instáveis, mas revela, ao mesmo tempo, a preocupação em procurar soluções, demonstrando capacidade de resolver problemas. Madsen (1999) salienta que, com frequência, os profissionais aludem à inexistência de mudança nestas famílias e à perpetuação dos seus padrões interaccionais ao longo de gerações. Em simultâneo, verifica-se que estas famílias enfrentam crises sucessivas e vão conseguindo seguir em frente, com mais ou menos facilidade e sucesso. A ilusão da não mudança para os profissionais decorre de esperarem uma determinada mudança, que os torna cegos a outras transformações.

Acresce que há evidência da prática e da investigação comunitária de que o modelo centrado nas competências é um instrumento eficaz para responder às necessidades das famílias multiproblemáticas pobres, por exemplo: Elizur (1996) demonstra que o envolvimento das famílias multiproblemáticas no processo de intervenção exige a mobilização dos recursos familiares e a capacitação da família, o que é alcançado pela partilha do poder e da responsabilidade; Cunningham e Henggeler (1999) mostram que o envolvimento das famílias e a eficácia da intervenção se relacionam com a identificação e reconhecimento das competências da família; Rojano (2004) coloca como objectivo da intervenção a construção de uma autobiografia das famílias focada nas competências.

\section{Objectivos}

O principal objectivo desta pesquisa é conhecer a percepção das famílias multiproblemáticas pobres acerca das suas competências e quais as soluções que descortinam para alcançar os seus objectivos de vida.

Estas finalidades são relevantes, dum ponto de vista teórico, pela escassez de estudos centrados nas competências destas famílias, e dum ponto 
de vista prático, porque os modelos de intervenção centrados nas competências se têm mostrado mais eficazes.

Além disso, na intervenção poderá haver a tendência para repetir o que se faz nas abordagens centradas nos défices, isto é, o profissional identifica as competências das famílias. Contudo, isto seria paradoxal, uma vez que considerar um sistema competente significa expressar confiança na existência de competências, apesar de aceitar que em certas ocasiões os sistemas não as sabem utilizar, em algumas áreas não as possuem, podem não reconhecer que as têm, estão impedidos ou privam-se de as usar (Ausloos, 1996). Acresce que comparar as competências de famílias pobres multiproblemáticas e não multiproblemáticas permite perceber o que as aproxima e distingue, o que é relevante em termos da intervenção.

\section{Metodologia}

\section{Amostra}

Este estudo envolve duas subamostras de famílias pobres: uma composta por famílias multiproblemáticas e outra por famílias não multiproblemáticas. A selecção da amostra foi efectuada a partir de um conjunto de 100 famílias que colaboram num outro estudo que realizamos junto de agregados socialmente vulneráveis acerca dos seus problemas e estratégias de enfrentamento. Na altura em que a amostra deste estudo foi recolhida (2003), as famílias tinham sido inquiridas pela terceira vez: na primeira inquirição recolheram-se dados acerca da sua história de vida, dos problemas que enfrentam e das estratégias que usam para os tentar resolver; nas reinquirições seguintes actualizou-se a informação. Assim, aquando do início deste estudo já existia informação, recolhida ao longo de 3 anos, que nos permitia seleccionar os participantes.

Os critérios de selecção foram os seguintes: i) as famílias foram consideradas pobres quando o agregado recebia o rendimento mínimo garantido (RMG) ou tinha um rendimento inferior ao ordenado mínimo nacional; ii) as famílias multiproblemáticas foram escolhidas quando equivaliam à definição de Cancrini, Gregorio e Nocerino (1997); iii) as famílias foram indicadas como não multiproblemáticas se não condiziam com a definição de Cancrini, Gregorio e Nocerino (1997), ou apresentavam apenas um dos aspectos dessa descrição. Foi decidido entrevistar o chefe da família, definido como o elo de ligação do agregado com a rede de apoio formal, pois este é o membro com que os profissionais fazem o diagnóstico da situação familiar (Sousa, 2004). 
A amostra é constituída por 60 chefes de família, divididos por duas subamostras: 32 pertencem a famílias multiproblemáticas pobres e 28 a famílias pobres não multiproblemáticas. A amostra foi caracterizada em relação a idade, sexo, habilitações académicas, situação na profissão e local de residência. A distribuição das subamostras pelas variáveis consideradas é idêntica dum ponto de vista estatístico (Quadro 1).

Quadro 1: Caracterização da amostra

\begin{tabular}{|c|c|c|}
\hline & $\begin{array}{l}\text { Famílias pobres não } \\
\text { multiproblemáticas }\end{array}$ & $\begin{array}{c}\text { Famílias multiproblemáticas } \\
\text { pobres }\end{array}$ \\
\hline $\mathbf{N}$ & 28 & 32 \\
\hline \multicolumn{3}{|l|}{ Idade $^{1}$} \\
\hline Média & 49,9 & 47,7 \\
\hline Desvio-padrão & 17,1 & 16,3 \\
\hline \multicolumn{3}{|l|}{$\operatorname{Sexo}(\%)^{2}$} \\
\hline Feminino & 75 & 81,3 \\
\hline Masculino & 25 & 18,7 \\
\hline \multicolumn{3}{|l|}{ Habilitações académicas $(\%)^{3}$} \\
\hline Sem escolaridade & 17,9 & 15,6 \\
\hline Até 4 anos de escolaridade & 46,4 & 56,3 \\
\hline Até 9 anos de escolaridade & 21,5 & 25 \\
\hline Secundário & 10,6 & 3,1 \\
\hline Superior & 3,6 & 0 \\
\hline \multicolumn{3}{|l|}{ Local de residência $(\%)^{4}$} \\
\hline Rural & 33,3 & 31,3 \\
\hline Periurbano & 49,9 & 53,1 \\
\hline Urbano & 16,9 & 15,6 \\
\hline \multicolumn{3}{|l|}{ Situação na profissão $(\%)^{5}$} \\
\hline Pensionista/reformado & 28,6 & 21,9 \\
\hline Estudante & 3,6 & 3,1 \\
\hline Doméstica & 21,4 & 28,1 \\
\hline Empregado & 28,6 & 25 \\
\hline Desempregado & 17,9 & 21,9 \\
\hline
\end{tabular}

1 As médias etárias das subamostras não são estatisticamente diferentes: Teste $t ; \mathrm{p}>0,05$.

2 As subamostras apresentam a mesma distribuição: $\chi^{2}(1)=1,36 ; p<1$.

3 A distribuição das subamostras é idêntica: $\chi^{2}(4)=9,0815 ; \mathrm{p}<0,10$.

4 As subamostras apresentam distribuições idênticas: $\chi^{2}(2)=2,7625 ; \mathrm{p}<1$.

5 As subamostras apresentam distribuições iguais: $\chi^{2}(4)=2,4768 ; p<1$. 


\section{Instrumento}

A experiência de inquirição com estas famílias tem-nos demonstrado que a utilização de escalas tipo Likert é inadequada a esta população. De facto, os inquiridos têm dificuldade em compreender os itens que exigem alguma abstracção, não entendem o significado de várias palavras e não conseguem distinguir entre as opções de resposta (por exemplo, não concordo, concordo pouco...). Assim, optou-se por desenvolver uma entrevista semiestruturada que permitisse aos entrevistados expressarem as suas opiniões e sentimentos. O guião da entrevista foi delineado com base nas abordagens centradas nas competências e na forma de questionamento que usam para que sujeitos e famílias identifiquem e activem as suas competências (Shazer et al., 1986; Shazer \& Berg, 1997; Egan, 1998; Saleebey, 2001). Nesta linha, esse fim é alcançado focando as questões em: aspectos positivos da vida familiar ou em áreas de competência que sentem valiosas e efectivas nas suas vidas; objectivos que consideram positivos e possíveis de atingir; estratégias ou soluções que estão a usar ou utilizaram no passado e se têm mostrado eficazes para ultrapassar problemas ou gerir pressões da vida quotidiana. Deste modo, os clientes são colocados na posição de especialistas na sua vida, em simultâneo, não se focam os problemas (apesar de não serem ignorados), pois tal poderia sugerir que o cliente é disfuncional. Portanto, o instrumento de recolha dos dados teve por base uma entrevista semiestruturada, baseada em 4 questões abertas (Quadro 2). Esta forma de questionamento tem-se mostrado eficaz, quer dum ponto de vista clínico, quer de investigação (cf. Douglas, Santisteban, McBride \& Szapocznik, 2001; Shazer, 1999).

Quadro 2: Questões e objectivos da entrevista

\begin{tabular}{l|l}
\hline \multicolumn{1}{c|}{ Questões } & \multicolumn{1}{c}{ Objectivos } \\
\hline $\begin{array}{l}\text { Identifique aspectos positivos no relaciona- } \\
\text { mento e funcionamento da sua família. }\end{array}$ & $\begin{array}{l}\text { Identificar competências e recursos perce- } \\
\text { bidos. }\end{array}$ \\
\hline $\begin{array}{l}\text { O que é para a sua família melhorar de vida? } \\
\text { Que objectivos têm no sentido de melhorar } \\
\text { de vida? }\end{array}$ & $\begin{array}{l}\text { Analisar quais os objectivos de vida para o } \\
\text { futuro estabelecidos pela família. }\end{array}$ \\
\hline $\begin{array}{l}\text { O que é preciso acontecer para que a vida da } \\
\text { sua família melhore? Ou como pode a sua } \\
\text { família alcançar os objectivos que a farão } \\
\text { melhorar de vida? }\end{array}$ & $\begin{array}{l}\text { Descortinar as soluções percebidas pela } \\
\text { familia (como agir em direcção aos objecti- } \\
\text { vos anteriores). }\end{array}$ \\
\hline $\begin{array}{l}\text { O que aconteceu na vida da sua família que a } \\
\text { tornou melhor? }\end{array}$ & $\begin{array}{l}\text { Identificar o que funcionou, no passado, na } \\
\text { família. }\end{array}$ \\
\hline
\end{tabular}

Baseado em: Shazer et al. (1986); Shazer \& Berg (1997); Egan (1998); Saleebey (1996; 2001). 


\section{Procedimentos}

Após a selecção das famílias a incluir na amostra, os chefes de cada família foram contactados pelos membros da equipa de investigação, no sentido de solicitar a sua colaboração no estudo (de salientar que os sujeitos já conheciam o investigador que os contactou, das entrevistas anteriores). Todas as famílias contactadas acederam em colaborar. Os elementos da equipa de investigação ( 3 psicólogas, 1 socióloga e 1 licenciada em ciências da educação) deslocaram-se à residência das famílias, onde realizaram as entrevistas, que foram gravadas e, posteriormente, transcritas. A duração média das entrevistas foi de 43 minutos (mínimo - 15 minutos; máximo - 70 minutos).

\section{Análise dos dados}

As entrevistas foram submetidas a análise de conteúdo em duas fases. Na primeira fase, procedeu-se à definição das categorias, que consistiu num processo interactivo de refinamento progressivo envolvendo dois psicólogos (membros da equipa de investigação). Inicialmente, cada investigador leu todas as entrevistas e, com base também na literatura (cf. secção 2), desenvolveu uma lista de categorias. Em seguida, os dois investigadores reuniram-se para comparar e discutir as propostas. Este processo foi repetido até chegarem a um acordo. Depois, esses investigadores classificaram 20 respostas (5 a cada questão) para confirmarem se as categorias eram adequadas. Uma vez que o sistema se adequava, organizaram uma lista das categorias e subcategorias (Quadro 3), definindo-as e dando alguns exemplos, que passaram aos investigadores envolvidos na segunda fase.

Na segunda fase, efectuou-se a classificação das respostas dos entrevistados, também, por dois juízes (outras 2 psicólogas). Cada um classificou cada resposta a cada questão, de modo independente. Em seguida, reuniram-se para comparar as classificações. O coeficiente de concordância rondou os 78,5\%, valor considerado elevado (Miles \& Huberman, 1984). Para os casos em que houve discordância, foi realizada uma análise e discussão conjunta, tendo-se chegado a acordo em todos os casos. 
Quadro 3: Categorias e subcategorias

\begin{tabular}{|c|c|}
\hline \multicolumn{2}{|l|}{$\begin{array}{l}\text { Categorias / } \\
\text { Subcategorias }\end{array}$} \\
\hline Contexto & $\begin{array}{l}\text { Refere-se ao meio no qual os comportamentos e as mensa- } \\
\text { gens acontecem e têm significado no seio familiar. }\end{array}$ \\
\hline Emprego & $\begin{array}{l}\text { Ter, arranjar ou ter arranjado um emprego estável ou melhor remu- } \\
\text { nerado. }\end{array}$ \\
\hline Saúde & $\begin{array}{l}\text { Ter boa saúde. Melhora no estado de saúde ou melhores cuidados } \\
\text { de saúde. }\end{array}$ \\
\hline Obter subsídios & $\begin{array}{l}\text { Receber ou ter recebido subsídios em bens ou dinheiro da socie- } \\
\text { dade-providência. }\end{array}$ \\
\hline Habitação & $\begin{array}{l}\text { Ter habitação com condições adequadas; ter recebido (receber) } \\
\text { habitação social; melhorar as condições de habitabilidade; pagar } \\
\text { renda mais barata. }\end{array}$ \\
\hline $\begin{array}{l}\text { Rendimentos (meios } \\
\text { próprios) }\end{array}$ & $\begin{array}{l}\text { Ganhar mais; ter uma ocupação secundária; obter rendimentos } \\
\text { através do mercado informal de emprego. }\end{array}$ \\
\hline Habilitações & $\begin{array}{l}\text { Ter estudado ou vir a estudar para ter melhores habilitações aca- } \\
\text { démicas. }\end{array}$ \\
\hline Orientação religiosa & Ter fé; fazer promessas que foram concedidas. \\
\hline Desenvolvimento familia & $\begin{array}{l}\text { Reporta-se às mudanças naturais da família enquanto grupo, } \\
\text { bem como às mudanças nos seus membros individuais. }\end{array}$ \\
\hline Vínc & $\begin{array}{l}\text { Manter ou construir uma boa ou melhor relação com os filhos; } \\
\text { conseguir recuperar a tutela dos filhos; ver os filhos crescer e } \\
\text { serem responsáveis. }\end{array}$ \\
\hline Vínculo conjugal & $\begin{array}{l}\text { Manter ou construir uma boa relação com o cônjuge; ausência de } \\
\text { violência doméstica. }\end{array}$ \\
\hline Relações de amizade & $\begin{array}{l}\text { Manter ou estabelecer novas relações de amizade; ter ou obter o } \\
\text { apoio de amigos. }\end{array}$ \\
\hline Funções expressivas & $\begin{array}{l}\text { Relativas à forma como os membros da família comunicam } \\
\text { entre si e à dimensão afectiva da família. }\end{array}$ \\
\hline roblemas & \multirow{2}{*}{$\begin{array}{l}\text { Ser capaz ou melhorar a capacidade de resolver os problemas. } \\
\text { Manter ou construir lealdade, respeito e apoio na família. }\end{array}$} \\
\hline União familiar & \\
\hline Funções instrumentais & $\begin{array}{l}\text { Actividades da família no sentido de promover as condições } \\
\text { para uma boa integração social e para o desenrolar quo- } \\
\text { tidiano das actividades familiares. }\end{array}$ \\
\hline Clarificação de papéis & \multirow{2}{*}{$\begin{array}{l}\text { Cada membro conhece e cumpre as suas funções. } \\
\text { Os elementos da família apoiam-se nas tarefas instrumentais do } \\
\text { quotidiano. }\end{array}$} \\
\hline Entreajuda nas tarefas & \\
\hline
\end{tabular}




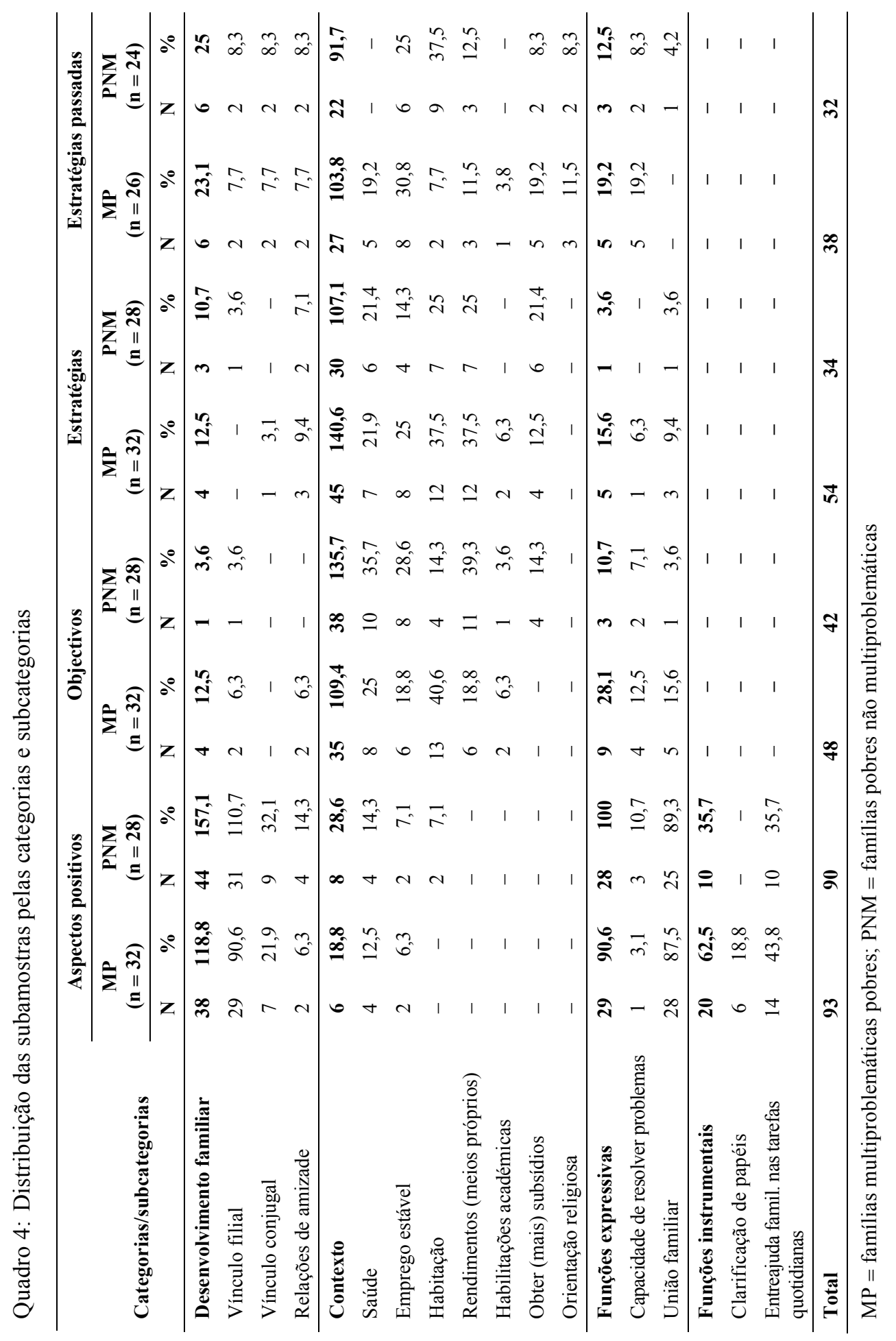




\section{Resultados}

Identifique aspectos positivos no relacionamento e funcionamento da sua família.

Todos os inquiridos identificaram aspectos positivos na vida familiar (Quadro 4). Quando se compara a distribuição das duas subamostras pelas categorias, verifica-se que as distribuições são diferentes $\left(\chi^{2}(3)=13,6150\right.$; $\mathrm{p} \leq 0,01)$. As famílias pobres não multiproblemáticas apresentam frequências superiores à outra subamostra em todas as categorias, com excepção das funções instrumentais em que a situação é inversa. Em qualquer dos casos, os aspectos positivos percepcionados incidem, principalmente, no desenvolvimento familiar e nas funções expressivas.

A mesma comparação, considerando as subcategorias, denota que as subamostras apresentam distribuições diferentes $\left(\chi^{2} \quad(10)=36,8567\right.$; $\mathrm{p} \leq 0,001)$. Os dados indicam que as famílias pobres não multiproblemáticas mencionam, com mais frequência, que os membros da outra subamostra, todas as subcategorias incluídas no desenvolvimento familiar, funções expressivas e contexto. Nas funções instrumentais ocorre a situação contrária. Há, ainda, 3 subcategorias em que as frequências são similares: união familiar (ronda os $88 \%$ ), saúde (cerca de 13\%) e emprego (em torno dos 6,5\%).

Os dados revelam que as 3 subcategorias mais frequentes coincidem nas duas subamostras: a mais referida é a união familiar; segue-se o vínculo filial (mais frequente entre as famílias não multiproblemáticas); e a entreajuda nas tarefas (frequência superior entre as famílias multiproblemáticas pobres).

Convém dar uma explicação adicional em relação ao vínculo conjugal. Esta subcategoria, de um modo geral, é descrita em ambas as subamostras pela expressão: "damo-nos bem". Contudo, nas famílias multiproblemáticas pobres assume, ainda, outro contorno, especialmente quando o entrevistado é uma mulher: 5 inquiridas descreveram a boa relação conjugal através da ausência de violência doméstica (por exemplo, "entre nós não há violência" ou "o meu marido não gosta de violência").

Em relação aos aspectos positivos mencionados com menos frequência, verifica-se que dois são comuns às subamostras: na categoria "contexto", emergem o emprego estável e a habitação. O outro aspecto menos referido é: nas famílias multiproblemáticas pobres a capacidade de resolução de problemas (funções expressivas) e nas famílias pobres não multiproblemáticas a clarificação de papéis (funções instrumentais). 


\section{Que objectivos tem a sua familia no sentido de melhorar de vida?}

Também nesta questão, todos os chefes de família identificaram sempre objectivos a alcançar para que a sua vida familiar prospere (Quadro 4). As subamostras distribuem-se de forma diferente pelas categorias $\left(\chi^{2}(2)=16,6936 ; p \leq 0,001\right)$. A categoria "contexto" é a mais referida por ambas as subamostras, mas com maior frequência entre os elementos das famílias pobres não multiproblemáticas. As categorias "funções expressivas" e "desenvolvimento familiar" apresentam, nas duas subamostras, frequências claramente inferiores ao "contexto", com frequências mais elevadas na subamostra das famílias multiproblemáticas pobres (não surgem objectivos no âmbito das funções instrumentais).

A comparação da distribuição das subamostras pelas subcategorias revela, igualmente, que são diferentes $\left(\chi^{2}(9)=54,8050 ; p \leq 0,001\right)$. Nas multiproblemáticas pobres todas as subcategorias das categorias "funções expressivas" e "desenvolvimento familiar" apresentam frequências superiores às obtidas pela outra subamostra. No caso das subcategorias incluídas em "contexto", as famílias multiproblemáticas pobres apenas apresentam frequências superiores à outra subamostra em duas subcategorias: melhoria da habitação e das habilitações académicas.

Algumas subcategorias exigem esclarecimentos, uma vez que apresentam contornos diversos nas subamostras. A referência à melhoria do estado de saúde está relacionada, nas famílias multiproblemáticas pobres, com tratamentos de alcoolismo no marido e/ou nos filhos ( 5 casos) e doenças crónicas ou situações de dependência (resultantes de doenças ou acidentes de viação/trabalho) (3 casos); nas famílias pobres não multiproblemáticas, as referências situam-se sempre no segundo aspecto (10 casos). Em relação ao vínculo filial, as 2 famílias multiproblemáticas pobres, que indicam este aspecto referem-se a "ter os filhos de volta" (pois perderam a sua tutela). A única situação na outra subamostra refere-se a conflitos com filhos adultos, que os pais gostariam de ultrapassar.

Sublinhe-se que as famílias pobres não multiproblemáticas indicam, como objectivo para melhorar de vida, a obtenção de mais subsídios por parte do sistema formal, o que nunca é referido pelas multiproblemáticas pobres.

Em termos globais, é de destacar que as subcategorias dos objectivos traçados pelos entrevistados apresentam um elemento de distinção: para as famílias multiproblemáticas pobres, a melhoria das condições de habitação destaca-se como o mais mencionado $(40,6 \%)$, enquanto apenas é referido por $14,3 \%$ dos membros da outra subamostra. 
Como pode a sua familia alcançar os objectivos que a farão melhorar de vida?

A comparação da distribuição das subamostras pelas categorias mostra que são similares $\left(\chi^{2}(2)=4,5799 ; \mathrm{p} \leq 0,20\right)$. Os dados indicam que ambas referem com mais frequência elementos contextuais, sendo as frequências das categorias "funções expressivas" e "desenvolvimento familiar" inferiores (a categoria "funções instrumentais" não é referida; Quadro 4).

Já quando se compara a distribuição das subamostras pelas subcategorias verifica-se que são diferentes $\left(\chi^{2}(10)=25,3710 ; p \leq 0,01\right)$. Na categoria "contexto", as famílias pobres não multiproblemáticas apenas apresentam frequências superiores à outra subamostra na subcategoria "obter subsídios". Na categoria "desenvolvimento familiar", as famílias multiproblemáticas pobres obtêm frequências superiores nas várias subcategorias, com excepção do vínculo filial, em que são similares. Quanto às subcategorias da categoria "funções expressivas", as famílias multiproblemáticas pobres apresentam frequências sempre superiores. Contudo, ambas as subamostras destacam as mesmas estratégias: melhoria dos rendimentos pelos meios próprios e incremento da situação habitacional.

Ainda é de sublinhar que as subcategorias "melhoria das relações conjugal e filial" são as menos referidas pelas subamostras, o que pode estar associado ao facto de os inquiridos indicarem estes aspectos como os mais positivos no funcionamento familiar e/ou pode denotar, apenas, que não as consideram estratégias relevantes para a melhoria da vida.

Convém referir que as estratégias enunciadas, pelas subamostras, estão coladas aos objectivos (por exemplo: melhorar de vida exige o incremento das condições de habitação e a estratégia é ter uma habitação melhor), indiciando pouca operacionalização, o que pode colaborar na falta de capacidade para resolver problemas.

\section{O que aconteceu que melhorou a vossa vida?}

Esta foi a questão em que os entrevistados evidenciaram mais dificuldade em responder, daí que 5 chefes de famílias multiproblemáticas pobres e 4 de famílias pobres não multiproblemáticas não tenham identificado nada no passado que tenha contribuído para a melhoria da vida familiar (Quadro 4).

A comparação da distribuição das subamostras pelas categorias revela similaridade $\left(\chi^{2}(2)=1,3528 ; p \leq 1\right)$. Os dados indicam que as subamostras referem com mais frequência elementos contextuais, sendo as referências às categorias "funções expressivas" e "desenvolvimento familiar" muito inferiores (não emerge a categoria "funções instrumen- 
tais"). A comparação da distribuição das subamostras pelas subcategorias mostra que são diferentes $\left(\chi^{2}(11)=55,8794 ; p \leq 0,01\right)$. Entre as subcategorias da categoria "contexto", evidencia-se que as multiproblemáticas pobres apresentam frequências superiores em relação à outra subamostra, com excepção de duas subcategorias: "melhoria dos rendimento por meios próprios" (frequências idênticas entre as subamostras) e "melhoria das condições de habitação" (frequência superior nas famílias pobres não multiproblemáticas). Na categoria "funções expressivas", as famílias multipróblemáticas pobres apresentam frequência superior na subcategoria "capacidade de resolução de problemas" e na subcategoria "união familiar" as frequências são idênticas. Nas subcategorias da dimensão "desenvolvimento familiar", as frequências apresentam valores idênticos nas subamostras.

Em suma, nas famílias multiproblemáticas pobres o que funcionou para a melhoria da sua vida foi terem arranjado um emprego estável e/ou melhor remunerado, enquanto para as famílias pobres não multiproblemáticas foi a melhoria das condições de habitação. No caso das condições de habitação, as famílias pobres não multiproblemáticas referem-se (6 casos) à atribuição de habitação social ou a benfeitorias (3 casos). As 3 famílias multiproblemáticas pobres que referem este aspecto fazem-no sempre em relação a benfeitorias.

Nas famílias multiproblemáticas pobres, destacam-se igualmente os benefícios decorrentes da atribuição de subsídios, da melhoria do estado de saúde e a capacidade de resolução de problemas. Surge, ainda, a orientação religiosa como um factor que ajudou as famílias no passado, neste caso os entrevistados referem-se a promessas feitas que foram concedidas. Mais uma vez, a formação e as habilitações académicas são pouco referidas como um factor que permitiu a melhoria de condições de vida, o que pode ser justificado pelo pouco investimento nesta área.

\section{Discussão dos resultados}

Ao considerarmos que a intervenção deve focar as competências das famílias, não podemos duvidar das suas percepções, pois tal seria negar a premissa inicial: se são competentes, sabem o que de adequado ocorre na família. Por isso, será útil adoptar uma atitude de respeito (Andolfi, 2000), que nasce da consciência do valor da percepção do outro e se manifesta num comportamento de atenção ao outro, obtendo a sua colaboração. Estas são as premissas em que baseamos a discussão dos resultados.

O principal resultado a destacar é a capacidade das famílias identificarem o que funciona na sua relação, indicarem objectivos de vida e estratégias para os alcançarem. Tal significa que as famílias têm competências, 
embora, como vamos analisar, possam estar de alguma forma paralisadas ou bloqueadas ao nível da sua activação.

Outro elemento de realce nas famílias em estudo é a percepção de que os aspectos mais positivos no seu funcionamento são a união familiar, o forte vínculo filial e a entreajuda nas tarefas quotidianas. Estas são das características mais apontadas na literatura como aspectos deficitários nestas famílias (cf. Kaplan, 1986; Linares, 1997). Neste contexto, dois padrões de interacção interventor-família podem emergir: o profissional designa a família como incompetente e esta sente-se injustamente julgada, o que pode gerar conflito ou apatia; o profissional designa a família como incompetente, esta, atendendo à opinião do especialista, começa a duvidar das competências que tinha como garantidas, tornando-se cada vez mais dependente dos serviços.

Paralelamente, verifica-se que entre os aspectos positivos identificados pelas famílias estão presentes alguns dos indicadores resultantes dos estudos sobre famílias saudáveis. Poder-se-á aventar que as famílias percepcionam esses aspectos positivos, mas que eles não estão presentes. Contudo, tem-se vindo a verificar que provavelmente esses elementos existem, mas são ofuscados, principalmente aos olhos dos profissionais, pelos contornos dramáticos dos problemas (Sousa, 2005; Madsen, 1999).

Pode, ainda, verificar-se que os aspectos positivos indicados pelos entrevistados se centram mais em factores internos (desenvolvimento familiar e funções expressivas) do que externos (contexto). De facto, as redes sociais informais destas famílias compreendem, por norma, membros com características muito próximas, por isso, pouco capazes de trazer recursos novos à família (Sousa, 2005). Por outro lado, com as redes formais é frequente a ocorrência de situações de conflito e apatia, que tendem a afastar as famílias (Imber-Black, 1988; Colapinto, 1995). O contexto é, então, percepcionado pelas famílias como uma dimensão frágil nas suas vidas.

Um outro elemento decorrente dos dados sugere que os objectivos de vida, as estratégias para os alcançar e o que funcionou no passado são colocados, com relevo, no contexto. Desta forma, parece que as famílias se colocam numa perspectiva compensatória: ao invés de procurarem activar as suas competências, usando-as como soluções ou estratégias, buscam na área mais frágil do seu funcionamento a resposta para os seus problemas. De facto, a maior dificuldade para a transformação no sentido da centração nas competências é que os modelos tradicionais compensatórios constituem a cultura e a linguagem dominantes (Gergen, Hoffman \& Anderson, 1996). Esta abordagem é partilhada por famílias e técnicos: procurar o que as famílias não têm (défices) e não apostar naquilo que existe e funciona (competências). Este é um dos factores que contribui para o bloqueio das 
famílias no uso das suas competências, que se pode rever no modo como o sistema de apoio formal se organiza para ajudar estas famílias e que tem, igualmente, impacto nesse bloqueio: quando as famílias procuram apoio para um problema, não se activam as competências das famílias, mas prescreve-se uma solução decidida pelos profissionais; quando as famílias procuram apoio para um problema, os profissionais efectuam diagnósticos onde encontram outros problemas, que a família não reconhece e sem os discutirem com a família (Sousa, 2004); algumas vezes, estas famílias não procuram apoio, mas este é dado, sem justificação.

Ainda, ao nível dos objectivos, nota-se que raramente são formulados em termos das relações familiares. Poder-se-ia colocar a hipótese de que as famílias não estão preocupadas com esses aspectos, mas tendo em consideração os resultados à primeira questão verifica-se que a família sente que nestes aspectos funciona bem.

Denota-se, igualmente, que as estratégias definidas para melhorar de vida carecem de operacionalidade, revelando a sua dificuldade em resolver problemas, o que é confirmado por as famílias não identificarem a capacidade de resolução de problemas como um dos seus aspectos fortes.

Passamos, agora, a analisar alguns dados de diferenciação entre as duas amostras estudadas. Os dados indicam que as famílias multiproblemáticas pobres, e as famílias pobres não multiproblemáticas se distribuem, em geral, de forma diferente pelas categorias e subcategorias nas várias questões. Assim, sugere-se que as subamostras têm percepções diferentes das suas competências. Desta comparação resultam alguns elementos relevantes.

Em primeiro lugar, a melhoria das condições de habitação no passado surge como um factor de relevo na vida das famílias pobres não multiproblemáticas. Provavelmente, por isso, esta subcategoria é, comparativamente, menos referida por estas famílias como um objectivo. Nas famílias multiproblemáticas pobres, o incremento das condições de habitação surge como um objectivo e uma estratégia para melhorar de vida. É incorrecto afirmar que a melhoria das condições de habitação elimina a situação de pobreza, porque as famílias em que a estratégia funcionou continuam pobres. Também não se sabe se funcionou como um ponto de viragem na multiproblematicidade, pois os dados não permitem conhecer se estas famílias pobres não multiproblemáticas eram multiproblemáticas. Todavia, os dados indicam que foi algo com impacto na melhoria da vida das famílias. De facto, o incremento da habitação tem um conjunto de efeitos secundários positivos, tais como: melhoria no estado de saúde (porque a habitação tem melhores condições de higiene), benefícios nas relações familiares (por existirem espaços mais individualizados e conforto), etc. No entanto, também acarreta efeitos adversos, como, por exemplo, distan- 
ciamento da rede informal, perda de alguma identidade relacional, maiores gastos financeiros, entre outros (Hespanha, Monteiro, Ferreira, Rodrigues, Nunes, van der Hoven \& Portugal, 2000).

Um segundo aspecto mostra que, nas famílias multiproblemáticas pobres, a obtenção de subsídios surge como uma estratégia eficaz no passado, mas pouco citada como forma de atingir os objectivos actuais; enquanto nas famílias pobres não multiproblemáticas essa subcategoria é, em comparação, menos referida como eficaz no passado e mais mencionada como um recurso para atingir os actuais objectivos. Assim, nas famílias multiproblemáticas um recurso que se mostrou eficaz não é re-activado; nas não multiproblemáticos, um apoio que não se evidenciou no passado é indicado como útil no presente. Este pode ser um marco do bloqueio das famílias multiproblemáticas pobres na activação das suas competências: têm dificuldade em aproveitar o que funcionou no passado para usar numa nova situação. Mas também se pode aventar outras possibilidades: os subsídios podem não ser entendidos como um meio adequado para os fins actuais; as famílias podem sentir-se, presentemente, mais capazes de atingir os objectivos de modo autónomo; das relações anteriores com os profissionais resultou algum mal-estar, apesar dos efeitos positivos. Em relação às famílias pobres não multiproblemáticas, sabemos que, no passado, não se mostrou uma estratégia relevante, mas que a querem utilizar: talvez porque a experiência com os serviços de protecção social seja menor e se sintam mais motivados a procurá-la, ou porque mantêm bons contactos e querem rentabilizá-los.

Apesar de termos vindo a destacar um conjunto de implicações práticas dos resultados, queremos salientar um aspecto de cariz mais global. Os resultados obtidos demonstram que as famílias em estudo têm tendência para solicitar ou esperar apoio contextual: uma casa melhor, um emprego, um subsídio... Contudo, os profissionais, embora atentos a estas dificuldades, tendem a eleger objectivos mais centrados na relação familiar, com especial foco na parentalidade (Linares, 1997). Assim se cria dissonância entre as necessidades sentidas pela família (contexto) e as prioridades eleitas pelos interventores (parentalidade), gerando-se um clima propício a conflitos: os profissionais tendem a interpretar as solicitações das famílias como uma forma de viver na dependência dos apoios sociais, sem criar recursos próprios; os profissionais decidem retirar os filhos da tutela dos seus pais ou, simplesmente, questionam a competência parental, esta situação é vivida como uma injustiça, levando a que a família se sinta mais incapacitada e incompetente (não se pode negar que, por vezes, os profissionais têm que tomar estas opções extremas, mas esta medida deveria ser acompanhada pelo reconhecimento dos laços entre pais e filhos, apesar das dificuldades de exercer o papel parental). 


\section{Conclusões}

As famílias multiproblemáticas pobres tendem a considerar que as suas competências se centram no interior do funcionamento familiar (e menos nas relações com o contexto), definem objectivos contextuais, mas sentem que é o esforço da família (e menos o apoio externo) que as pode ajudar a melhorar de vida. Sentem que as suas competências são a união familiar e o forte vínculo filial e percepcionam que a melhoria de vida passa, sobretudo, por melhores condições de habitação, um melhor emprego e mais saúde. Demonstram vontade de melhorar a sua vida pelos próprios meios, sentem que os problemas de saúde que vivem são o maior obstáculo à melhoria de vida, pois impedem-nos de trabalhar (ou ter um emprego melhor), o que acarreta a impossibilidade de melhorar os rendimentos e, assim, conseguir melhorar as condições de vida. Em suma, as famílias multiproblemáticas pobres identificam competências no seu funcionamento, mas parecem bloqueadas na activação das suas competências para atingir os seus objectivos. Tal parece decorrer da incorporação de modelos tradicionais: tal como os profissionais, também as famílias procuram soluções compensatórias.

As famílias multiproblemáticas pobres e as pobres não multiproblemáticas diferenciam-se ao nível das competências, designadamente, as multiproblemáticas pobres tendem a usar menos como recurso a obtenção de subsídios e apontam como objectivo mais premente a melhoria das condições de habitação.

Ao nível das limitações deste estudo, destaca-se o facto de a amostra ser reduzida; apenas é considerado o ponto de vista de um dos elementos da família. Contudo, este estudo abre algumas perspectivas de pesquisa interessantes: comparar o ponto de vista de profissionais e famílias acerca das competências das famílias; comparar as competências de famílias multiproblemáticas pobres e não pobres; usar medidas de percepção das competências baseadas nos vários membros da família e na sua interacção; alargar o tamanho da amostra; utilizar diferentes instrumentos de análise de competências para comparar os resultados.

\section{Referências}

Andersen, T. (1995). Reflecting process: Acts of informing and forming. In S. Friedman (Ed.), The reflecting team in action (pp. 11-37). Nova Iorque: Guilford Press.

Andolfi, M. (2000). El coloquio relacional. Barcelona: Paidós.

Ausloos, G. (1996). A competência das famílias. Lisboa: Climepsi. 
Barnhill, L. (1979). Healthy family systems. The Family Coordinator, 28, 94-100.

Beavers, W. (1985). Successful marriage. Nova Iorque: W. W. Norton.

Cancrini, L., Gregorio, F., \& Nocerino, S. (1997). Las familias multiproblemáticas. In M. Coletti \& J. Linares (Eds.), La intervención sistémica en los servicios sociales ante la familia multiproblemática (pp. 45-82). Barcelona: Paidós.

Colapinto, J. (1995). Dilution of family in social services. Family Process, 34, 59-74 .

Cunningham, P., \& Henggeler, S. (1999). Engaging multi-problem families in treatment: Lessons learned throughout the development of multisystemic therapy. Family Process, 38, 265-281.

Curran, D. (1983). Traits of a healthy family. Minneapolis, MI: Winston Press.

Dallos, R., \& Hamilton-Brown, L. (2000). Pathways to problems. Journal of Family Therapy, 22, 375-393.

Douglas, J., Santisteban, D., McBride, C., \& Szapocznik, J. (2001). Brief strategic family therapy versus community control. Family Process, 40, 313-332.

Egan, G. (1998). The skilled helper. Pacific Grove, CA: Brooks/Cole.

Elizur, Y. (1996). Involvement, collaboration and empowerment. Family Process, 35, 191-210.

Epstein, N., Bishop, D., Miller, I., \& Keitner, G. (1993). The McMaster model. In F. Walsh (Ed.), Normal family processes (pp. 138-160). Nova Iorque: The Guilford Press.

Fruggeri, L. (1996). El proceso terapéutico como construcción social. In S. McNamee \& K. Gergen (Org.), La terapia como construcción social (pp. 61-74). Barcelona: Paidós.

Gergen, K., Hoffman, L., \& Anderson, H. (1996). Is diagnosis a disaster? A constructionist trialogue. In F. Kaslow (Ed.) Relational diagnosis. Nova Iorque: Wiley.

Haley, J. (1996). Learning \& teaching therapy. Nova Iorque: Guilford Press.

Hespanha, P., Monteiro, A., Ferreira, A., Rodrigues, F., Nunes, M., van den Hoven, R., \& Portugal, S. (2000). Entre o estado e o mercado. As fragilidades das instituições de protecção social em Portugal. Coimbra: Quarteto.

Hines, P. (1989). The family life cycle of poor black families. In B. Carter \& M. McGoldrick (Eds), The changing family life cycle (pp. 513-544). Boston: Allyn \& Bacon.

Hoffman, L. (1971). Deviation: Amplifying processes in natural groups. In J. Haley (Ed.), Changing families (pp. 58-89). Nova Iorque: Grune \& Stantton.

Imber-Black, E. (1988). Families and larger systems. Nova Iorque: The Guilford Press.

Kaplan, L. (1986). Working with multi-problem families. Nova Iorque: Simon \& Schuster.

Kelley, P. (1994). Developing healthy stepfamilies. Nova Iorque: Haworth Press.

Linares, J. (1997). Modelo sistémico y familia multiproblemática. In M. Coletti \& J. Linares (Comps.), La intervención sistémica en los servicios sociales ante la familia multiproblemática (pp. 23-44). Barcelona: Paidós. 
Madsen, W. (1999). Therapy with multi-stressed families. Londres: Guilford.

Maturana, H., \& Varela, F. (1980). Autopoïesis and cognition. Boston: Reidel.

Miles, M., \& Huberman, A. (1984). Qualitative data analysis. Beverly Hills: SAGE.

Nagy, I., \& H. Zuk (1967). Family therapy and disturbed families. Palo Alto: Science \& Behavior Books.

O’Hanlon, W., \& Weiner-Davis, M. (1989). En busca de soluciones. Barcelona: Paidós.

O’Hanlon, W. (1993). Possibility therapy. In S. Gilligan \& R. Price (Eds.), Therapeutic conversations (pp. 3-17). Nova Iorque: Worton \& Company.

Olson, D. (1990). Clinical rating scale for circumplex model. St. Paul: Family Social Science, University of Minnesota.

Olson, D., Larsen, A., \& McCubbin, H. (1989). Family strengths. In D. Olson (Ed.), Family inventories. St. Paul: Family Social Science, University of Minnesota.

Rojano, R. (2004). Practice of community family therapy. Family Process, 43, 59$-77$.

Saleebey, D. (2001). The diagnostic strengths manual? Social Work, 46, 183-187

Saleebey, D. (1996). The strengths perspective in social work practice. Social Work, 41, 296-305.

Satir, V. (1967). Conjoint family therapy. Palo Alto: Science and Behavior Books.

Shazer, S., \& Berg, I. (1997). What works? Remarks on research aspects of solution-focused brief therapy. Journal of Family Therapy, 19, 121-124.

Shazer, S. (1999). En un origen las palabras eran magia. Barcelona: Gedisa.

Shazer, S., Berg, F., Lipchik, E., Nunnaly, E., Molnar, A., Gingerich, W., \& Weiner-Davis, M. (1986). Brief therapy: Focused solution development. Family Process, 25, 207-221.

Sousa, L. (2004). Diagnósticos e problemas: Uma perspectiva sistémica centrada nas famílias multiproblemáticas pobres. Psychologica, 37, 147-167.

Sousa, L. (2005). Famílias multiproblemáticas. Coimbra: Quarteto.

Stinnett, N. (1979). Building family strengths. Lincoln: University of Nebraska Press.

Whitaker, C. (1989). Midnight musings of a family therapist. Nova Iorque: Norton and Company. 